Karen L. Mohlke • Anne U. Jackson • Laura J. Scott

Erin C. Peck · Yong D. Suh $\cdot$ Peter S. Chines

Richard M. Watanabe $\cdot$ Thomas A. Buchanan

Karen N. Conneely • Michael R. Erdos • Narisu Narisu

Sareena Enloe $\cdot$ Timo T. Valle $\cdot$ Jaakko Tuomilehto

Richard N. Bergman $\cdot$ Michael Boehnke

Francis S. Collins

\title{
Mitochondrial polymorphisms and susceptibility to type 2 diabetes-related traits in Finns
}

Received: 23 June 2004 / Accepted: 12 July 2005 / Published online: 2 September 2005

(C) Springer-Verlag 2005

\begin{abstract}
Mitochondria play an integral role in ATP production in cells and are involved in glucose metabolism and insulin secretion, suggesting that variants in the mitochondrial genome may contribute to diabetes
\end{abstract}

E. C. Peck · Y. D. Suh · P. S. Chines - M. R. Erdos

N. Narisu $\cdot$ S. Enloe $\cdot$ F. S. Collins

Genome Technology Branch, National Human Genome Research Institute, Bethesda, MD, USA

A. U. Jackson · L. J. Scott · K. N. Conneely $\cdot$ M. Boehnke Department of Biostatistics, School of Public Health, University of Michigan, Ann Arbor, MI, USA

R. M. Watanabe

Department of Preventive Medicine, Keck School of Medicine, University of Southern California, Los Angeles, CA, USA

T. A. Buchanan · R. N. Bergman

Department of Physiology and Biophysics, Keck School of Medicine, University of Southern California,

Los Angeles, CA, USA

T. T. Valle $\cdot$ J. Tuomilehto

Diabetes and Genetic Epidemiology Unit,

Department of Epidemiology and Health Promotion, and Department of Biochemistry,

National Public Health Institute,

Helsinki, Finland

J. Tuomilehto

Department of Public Health, University of Helsinki,

Helsinki, Finland

J. Tuomilehto

South Ostrobothnia Central Hospital, Seinäjoki, Finland

K. L. Mohlke ( $\square)$

Department of Genetics, University of North Carolina, 4109-F Neurosciences Research Building,

103 Mason Farm Road, CB\#7264,

27599-7264 Chapel Hill, NC, USA

E-mail: mohlke@med.unc.edu

Tel.: + 1-919-9662913

Fax: + 1-919-9663630 susceptibility. In a study of Finnish families ascertained for type 2 diabetes mellitus (T2DM), we genotyped single nucleotide polymorphisms (SNPs) based on phylogenetic networks. These SNPs defined eight major haplogroups and subdivided groups $\mathrm{H}$ and $\mathrm{U}$, which are common in Finns. We evaluated association with both diabetes disease status and up to 14 diabetes-related traits for 762 cases, 402 non-diabetic controls, and 465 offspring of genotyped females. Haplogroup J showed a trend toward association with T2DM affected status (OR $1.69, P=0.056)$ that became slightly more significant after excluding cases with affected fathers (OR 1.77, $P=0.045)$. We also genotyped non-haplogroup-tagging SNPs previously reported to show evidence for association with diabetes or related traits. Our data support previous evidence for association of T16189C with reduced ponderal index at birth and also show evidence for association with reduced birthweight but not with diabetes status. Given the multiple tests performed and the significance levels obtained, this study suggests that mitochondrial genome variants may play at most a modest role in glucose metabolism in the Finnish population. Furthermore, our data do not support a reported maternal inheritance pattern of T2DM but instead show a strong effect of recall bias.

\section{Introduction}

Type 2 diabetes mellitus (T2DM) is a common metabolic disorder affecting approximately $8 \%$ of the US adult population (Mokdad et al. 2003), a similar proportion of the Finnish population (Tuomilehto et al. 1991), and more than 135 million people worldwide (King et al. 1998). The disorder is characterized by impaired glucose homeostasis, insulin resistance, and decreased pancreatic beta cell function. There is strong evidence for a genetic component (Newman et al. 1987; 
Rich 1990; Kaprio et al. 1992), and several variants in the nuclear genome have been identified that show association with disease susceptibility (Florez et al. 2003; McCarthy 2004). Given the small effect of these variants, many more remain to be identified.

Unmistakable mitochondrial defects exist in some individuals affected with diabetes. Mitochondria are responsible for producing ATP by oxidative phosphorylation, and this intracellular ATP production is tightly linked to insulin secretion from pancreatic beta cells (reviewed by Maechler and Wollheim 2001). Mutations in mitochondrial DNA cause more than 40 syndromes that involve hyperglycemia (Barrett 2001). At the RNA level, a subset of coordinately regulated nuclear-encoded genes for mitochondrial proteins exhibit decreased expression in human diabetic muscle (Mootha et al. 2003), and a few genes involved in oxidative phosphorylation exhibit increased expression, perhaps to compensate for decreased function (Antonetti et al. 1995). Mice lacking the mitochondrial transcription factor TFAM in pancreatic beta cells exhibit reduced glucosestimulated insulin secretion, beta-cell loss, and diabetes (Silva et al. 2000). Moreover, skeletal muscles from diabetic individuals exhibit reduced activity of oxidative phosphorylation enzymes and impaired mitochondrial bioenergetic capacity (Simoneau and Kelley 1997; Kelley et al. 2002). In insulin-resistant individuals, mitochondrial phosphorylation is reduced $30 \%$ compared to controls (Petersen et al. 2004).

Evidence exists for a bias toward maternal transmission of T2DM. Among 16 studies of T2DM inheritance, 11 show evidence of greater maternal transmission, five studies show no difference between maternal and paternal transmission, and none show an excess of paternal transmission (reviewed by Alcolado et al. 2002). On one hand, these results could have been subject to confounding issues such as missing data, recall of parental affection status, selective mortality, gender bias in seeking medical care, erroneous paternity, and gender differences in the age of death. On the other hand there are several possible explanations for excess maternal inheritance of T2DM including long-term effects of exposure to maternal diabetes in utero (Pettitt et al. 1988; Silverman et al. 1991), imprinting, X-linked genes, and maternal transmission of mitochondrial variants.

Mitochondrial DNA mutations that cause rare cases of maternally inherited diabetes may affect the structure, stability, and activity of proteins in the electron transport chain. This in turn leads to reduced oxidative phosphorylation and less ATP production, while increasing production of reactive oxygen species. A variant at nucleotide 3243 has been shown to be responsible for maternally inherited diabetes and deafness (MIDD) (Reardon et al. 1992; van den Ouweland et al. 1992). The A3243G point mutation in a tRNA for leucine causes reduced binding of the amino acid to its transfer RNA, leading to decreased synthesis of proteins necessary for oxidative phosphorylation and reduced glucose-stimulated insulin secretion (Suzuki et al. 1997). At least 25 additional mitochondrial variants have been proposed to be associated with diabetes (Maechler and Wollheim 2001; Alcolado et al. 2002). Most of these variants are rare and many are associated with additional traits such as deafness, neurological symptoms, or myopathy. One common variant, T16189C, with an allele frequency of $6-10 \%$ in individuals from the United Kingdom, has been reported to be associated with T2DM, higher fasting insulin levels, and lower ponderal index, which is a measure of body mass in infants (Poulton et al. 1998, 2002b; Casteels et al. 1999).

As part of our Finland United States Investigation of NIDDM Genetics (FUSION) study, we are evaluating linkage and evidence for association of variants with T2DM and related traits. The present analyses were conducted to test the hypothesis that common mitochondrial lineages have a significant effect on susceptibility to T2DM or a related trait, or that the variants have an effect on the expression of disease, as has been observed for Leber's hereditary optic neuropathy and haplogroup J (Torroni et al. 1997; Brown et al. 2002). We genotyped 32 single nucleotide polymorphisms (SNPs) tagging the major Finnish haplogroups and subgroups of haplogroups $\mathrm{H}$ and $\mathrm{U}$ to evaluate whether mitochondrial variants influence susceptibility in a significant portion of the population. Compared to other Europeans, haplogroup U and especially subgroup U5 are more common in Finns (Richards et al. 1996; Torroni et al. 1996; Finnila et al. 2001). We also tested five variants described previously to be associated with diabetes or a related trait. We found a trend toward association between diabetes status and haplogroup $\mathrm{J}$, as well as association between several haplogroups and intermediate phenotypic traits, although a large number of statistical tests (517, not independent) were performed. Our data also support the effect of the T16189C variant on low body mass at birth.

\section{Materials and methods}

\section{Sample}

Sample ascertainment in the FUSION study, mostly through affected sibling pairs, has been described previously (Valle et al. 1998; Silander et al. 2004). Preference was given to families with zero or one affected parent over families with two affected parents. Affection status in nearly all parents of probands and spouses was based on recall by the probands and spouses since most of their parents were deceased at the time of study. Affection status of probands, their spouses, and their offspring was based on medical records and oral glucose tolerance tests (OGTT) (Valle et al. 1998). In this study, we genotyped T2DM cases collected in separate waves of sampling designated FUSION 1 (532 cases) and FUSION 2 (263 cases) (Silander et al. 2004), controls consisting of 190 normoglycemic spouses of FUSION 1 
cases and 225 elderly normal glucose tolerant individuals (by OGTT at ages 65 and 70), and 465 offspring of genotyped females. Informed consent was obtained from each study participant, and the study protocol was approved by the Ethics Committee or Institutional Review Board in each of the participating centers. All individuals have been described previously (Valle et al. 1998; Silander et al. 2004). Genotypes were successfully performed and major haplogroups assigned for 762 of the 795 T2DM cases and 402 of the 415 controls (see below).

\section{Genotyping}

Thirty-two SNPs characteristic of Finnish mitochondrial haplogroups were selected based on previous reports (Macaulay et al. 1999; Finnila et al. 2001; MacaMeyer et al. 2001; Herrnstadt et al. 2002). Only coding region SNPs were selected, and preference was given to SNPs reported more than once to characterize a haplogroup. We preferred SNPs diagnostic for a haplogroup rather than those present in two or more groups by avoiding, when possible, SNPs known to be the site of recurrent mutation. For some haplogroups, two SNPs were selected to allow greater confidence of haplogroup assignment.

Five additional SNPs previously reported to be associated with T2DM or a related trait were genotyped as well. Candidate SNPs included A8296G, A12026G, T14577C, and T16189C; no results are shown for SNPs A8296G and T14577C, as these were not polymorphic in our sample. The A3243G variant accounting for MIDD was genotyped to confirm that all cases of MIDD had been excluded. To follow-up initial evidence of association with T16189C, we also genotyped SNPs T16186C and T16192C. All nucleotide positions are based on the revised Cambridge reference sequence (Andrews et al. 1999), with the reference and alternate nucleotides listed before and after the position, respectively. When shown, frequencies refer to the alternate nucleotide.

Single nucleotide polymorphisms located under oligonucleotides for PCR or primer extension can lead to failed genotypes, which could affect haplogroup assignment. To increase the chance that primers would anneal consistently, all known mitochondrial SNPs in Finns (Finnila et al. 2001) were noted in the sequence prior to primer design and primers spanning these sites were avoided when possible. Specifically, our SNP genotyping assay design required an extension primer located adjacent to the SNP. If both potential extension primers would span additional SNPs, we chose to design the primer across the SNP corresponding to the more distantly related haplogroup.

Single nucleotide polymorphisms were genotyped by homogeneous MassEXTEND reaction using the MassARRAY System (Sequenom, San Diego, CA, USA) as previously described (Mohlke et al. 2002). For the candidate SNP at nucleotide position 16189 and nearby SNPs at 16186 and 16192 in the highly variable D-loop region, we used previously described primers named 'Seq3' and 'Seq5' (Marchington et al. 1996). For all mitochondrial SNPs tested, on average $98.0 \%$ of attempted genotypes were successful. Among 3323 blinded duplicate genotype pairs, we observed zero discrepancies, for an estimated genotyping reproducibility of $>99.98 \%$. Heteroplasmy was observed for the two MIDD samples harboring the A3243G variant and one sample with the T1189C variant; our genotyping method would not have detected heteroplasmy below $\sim 10 \%$.

\section{Classification of haplogroups}

Based on four previous reports (Macaulay et al. 1999; Finnila et al. 2001; Maca-Meyer et al. 2001; Herrnstadt et al. 2002), we selected SNPs and identified haplogenotypes, the SNP genotype patterns that characterize particular haplogroups (Table 1). We included major haplogroups common in the Finnish population, and considered haplogroup $\mathrm{K}$ as a subgroup to haplogroup $\mathrm{U}$ (Richards et al. 1998). For major haplogroups $\mathrm{H}$ and $\mathrm{U}$ that are common in the Finnish population, additional SNPs were selected to define subgroups. When SNPs were selected for subdivisions not previously named in the literature, we designated the subgroup using the SNP position. In three instances, previously identified recurrent mutation resulted in two haplogenotypes characteristic of the same haplogroup (members of haplogroup J may have G or A at 3010, subgroup U4 may have $A$ or $G$ at 11467 , and haplogroup X may have $G$ or $A$ at 13708).

We assigned major haplogroups and subgroups based on haplogenotype pattern (Table 1). Missing data were tolerated if a haplogenotype pattern was consistent with only a single haplogroup. After initial attempts to assign haplogroups, some samples did not match any expected haplogenotypes or matched haplogenotypes for more than one haplogroup due to missing data or recurrent mutation or both. We expanded the definition of existing haplogenotype patterns when we identified at least four samples consistent with recurrent mutation, including that G9055A appears in haplogroup $\mathrm{H}$ (seven samples) and that A14793G appears in haplogroup V (five samples). Individual samples were removed from the analysis if no haplogroup could be assigned, either because too many genotypes were missing or because the haplogenotypes showed discrepancies from known haplogroup patterns suggestive of rare recurrent mutation.

Offspring were not genotyped directly; instead, maternal haplogroups were assigned to their offspring. The chance of incorrect assignment due to inheritance inconsistency is small because these families were previously typed for $>400$ microsatellites spanning the nuclear genome and inconsistent families were removed (Ghosh et al. 2000; Silander et al. 2004). 


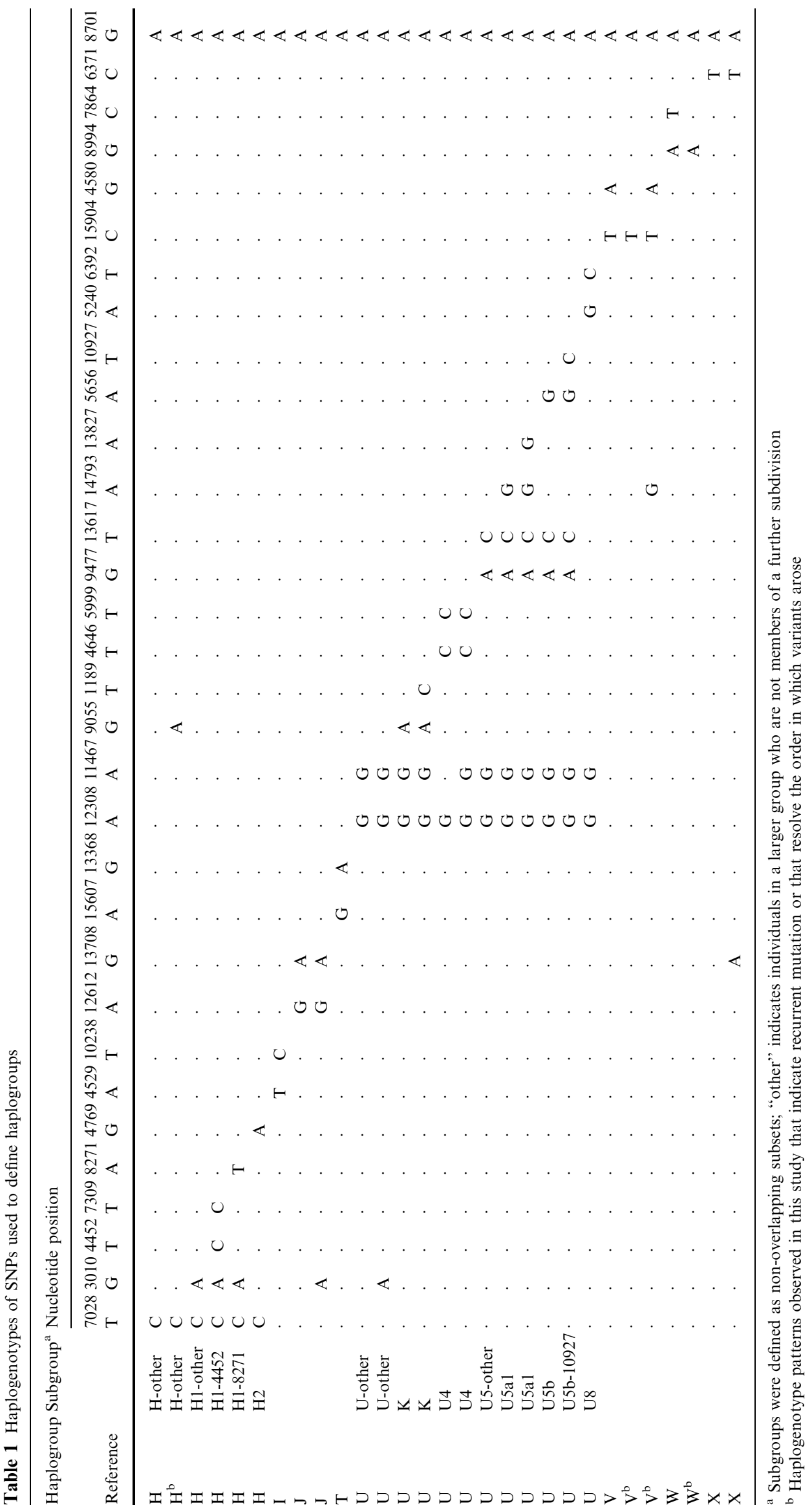




\section{Statistical analysis}

For tests of association of major haplogroup with T2DM status, 762 T2DM cases from FUSION 1 and FUSION 2 ascertainment for which a major haplogroup could be assigned were combined and analyzed together, as were 402 unaffected spouse and elderly normoglycemic controls. Fewer samples, 743 cases and 390 controls, could be classified into a subgroup because of missing genotype data. The eight major haplogroups, 13 subgroups, and the polymorphic candidate SNP 16189 were tested for association with T2DM using logistic regression.

From the diabetes-related quantitative traits collected as part of the FUSION study (Valle et al. 1998), we selected traits for analysis most likely to be affected by mitochondrial mutations. Not all traits were collected for all sample sets (cases, unaffected spouses, elderly controls, and offspring), and some individuals within a sample set were not measured for a particular trait. Traits collected and analyzed in all sample sets were body-mass index (BMI), waist-to-hip ratio (WHR), fasting glucose, and fasting insulin. Traits collected and analyzed in cases only were age-of-onset, duration of diabetes, and Cpeptide levels. Traits measured and analyzed in spouses and offspring only were glucose and insulin levels at hour two of an OGTT, change in insulin between fasting and $2 \mathrm{~h}$ during the OGTT, and traits from minimal model analysis of a frequently sampled intravenous glucose tolerance (FSIGT) test including insulin sensitivity, acute insulin response to glucose, glucose effectiveness, and disposition index. Traits measured and analyzed only in offspring were ponderal index at birth, birthweight, and plasma free fatty acids. Traits were transformed to approximate normality when necessary.

We tested for association between haplogroups and T2DM using a $2 \times n$ test of independence (Ghosh et al. 2000). Quantitative trait associations with SNPs and haplogroups were tested using analysis of variance with adjustment for age, sex, and BMI, except that weightrelated traits were not adjusted for BMI and diabetes duration and age at diagnosis were not adjusted for age. We used Satterthwaite's method to account for potentially unequal variances in the subgroups with and without each mitochondrial variant. When fewer than ten samples with a given haplogroup had measured trait values, the haplogroup was not tested for association with that trait. Importantly, this sample size restriction means that the spouse and elderly control sample sets were only analyzed for six and eight traits, respectively. To account for the correlation between offspring (mean $2.6 \pm 1.3$ offspring per family), we used a mixed model approach (Littell et al. 1996) with family as a random effect. To test for consistency of results in small subgroup sizes we also tested the most significant results using an empirical variance estimator (Zeger and Liang 1986) within a generalized estimating approach (GEE) or mixed model approach. In general we found relatively good agreement, with the exception of haplogroup $\mathrm{V}$ for glucose effectiveness as noted in Table 3. After our ini- tial analysis, we repeated analyses excluding 74 sibships from the proband generation that had affected fathers and unaffected mothers and were, therefore, less likely to have diabetes due to maternally inherited variants. $P$ values were not corrected for multiple comparisons.

To address the hypothesis that a homopolymeric cytosine run at positions $16184-16193$ is associated with quantitative traits in offspring, we compared individuals assigned $\mathrm{C}$ at 16186, 16189, and 16192 to those assigned $\mathrm{T}$ at one or more of these positions (Poulton and Das 2004). For this analysis, we only used offspring with a genotype assigned at 16189 , and we excluded individuals with $\mathrm{C}$ at 16189 but missing genotypes at $16186(n=13)$ or $16192(n=31)$. This strategy allowed us to compare individuals whose haplogenotype assignment is certain but excludes individuals that may be missing genotypes due to SNPs at nearby sites under genotyping primers.

To compare proportions of individuals exhibiting maternal and paternal inheritance, we performed twoby-two $\chi^{2}$ tests.

\section{Results}

Mutations in mitochondrial DNA (mtDNA) accumulate sequentially over hundreds or thousands of generations, allowing related lineages, or haplogroups, to be classified in a hierarchical structure. We used phylogenetic networks constructed from completely sequenced mitochondrial genomes to identify eight common Finnish haplogroups and select SNPs that tag these groups (Macaulay et al. 1999; Finnila et al. 2001; Maca-Meyer et al. 2001; Herrnstadt et al. 2002). We chose haplogroup-specific variants where possible, or variants for which additional occurrences are rare (Table 1). Major haplogroups could be assigned for 762 of 795 T2DM cases and 402 of 415 controls. These 762 T2DM cases had a study age of $63.9 \pm 7.5$ (mean \pm standard deviation), age of diagnosis of $50.9 \pm 8.3$, a BMI of $30.0 \pm 4.5$, and were $44.1 \%$ female. These 402 controls had a study age of $66.3 \pm 6.5$, a BMI of $27.8 \pm 4.4$ and were $59.5 \%$ female. The frequency of haplogroup $\mathrm{J}$ was slightly greater in cases of T2DM (0.070) than controls $(0.042$, Table 2), although this difference was not quite statistically significant at the 0.05 level $(\mathrm{OR}=1.69, P=0.056)$. After excluding 74 cases with affected fathers, evidence for association strengthened slightly $(\mathrm{OR}=1.77$, $P=0.045)$. Using a general $2 \times n$ test for independence we found no significant differences in the haplogroup frequencies between cases and controls $(P=0.60)$.

To test association within common Finnish haplogroups H and U (Finnila et al. 2001), we selected SNPs to characterize a total of 13 subgroups. Some SNPs tag previously named subgroups, such as H1. For further subdivisions, we indicated the group by an SNP position in the reference sequence, such as H1-4452. The frequencies of subgroups $\mathrm{H} 1-8271$ and $\mathrm{K}$ were slightly greater in cases of T2DM than controls, although these differences were not statistically significant (Table 2). 
Table 2 Haplogroup frequencies and evidence for T2DM association in cases and controls

\begin{tabular}{|c|c|c|c|c|c|}
\hline Haplogroup & Subgroup $^{\mathrm{a}}$ & Case frequency ${ }^{\mathrm{b}}$ & Control frequency ${ }^{\mathrm{c}}$ & $P$ value & Odds ratio $\left(\mathrm{CI}^{\mathrm{d}}\right)$ \\
\hline \multirow[t]{5}{*}{$\mathrm{H}$} & & 0.491 & 0.485 & 0.852 & $1.02(0.80-1.30)$ \\
\hline & H1-4452 & 0.034 & 0.046 & 0.302 & $0.72(0.39-1.33)$ \\
\hline & Other H1 & 0.164 & 0.144 & 0.362 & $1.17(0.83-1.65)$ \\
\hline & $\mathrm{H} 2$ & 0.043 & 0.051 & 0.534 & $0.83(0.47-1.47)$ \\
\hline & Other $\mathrm{H}$ & 0.190 & 0.210 & 0.412 & $0.88(0.65-1.19)$ \\
\hline \multirow[t]{6}{*}{$\mathrm{U}$} & & 0.266 & 0.284 & 0.532 & $0.92(0.70-1.20)$ \\
\hline & $\mathrm{K}$ & 0.050 & 0.028 & 0.077 & $1.81(0.91-3.58)$ \\
\hline & U4 & 0.026 & 0.044 & 0.108 & $0.57(0.30-1.12)$ \\
\hline & U5a1 & 0.035 & 0.054 & 0.138 & $0.64(0.35-1.15)$ \\
\hline & U5b-10927 & 0.066 & 0.056 & 0.526 & $1.18(0.70-1.98)$ \\
\hline & $\mathrm{U} 5 \mathrm{~b}$ & 0.047 & 0.062 & 0.305 & $0.75(0.44-1.28)$ \\
\hline $\mathrm{X}$ & & 0.018 & 0.017 & 0.907 & $1.06(0.42-2.64)$ \\
\hline
\end{tabular}

"Subgroups were defined as non-overlapping subsets. "Other" indicates individuals in a larger group who are not members of a further subdivision. Subgroups without names are labeled with the nucleotide position of the defining SNP

After excluding 74 cases with affected fathers, the association with $\mathrm{H} 1-8271$ became slightly more significant $(\mathrm{OR}=2.07, P=0.057)$, while the association with $\mathrm{K}$ did not $(\mathrm{OR}=1.71, P=0.117)$.

The eight haplogroups and 13 subgroups were tested for association with T2DM-related traits in cases, spouse controls, elderly controls and offspring, as described in the methods. Of the 130, 94, 32, and 203 tests performed in cases, unaffected spouses, elderly controls, and offspring respectively, 3.1, $1.1,0$ and $3.0 \%$ were significant at the 0.05 level. This is less than expected by chance, but many of the traits are correlated, which reduces the effective number of independent tests. Traits showing nominally significant $(P<0.05)$ evidence for association with a haplogroup are shown in Table 3.

We also tested the A3243G SNP that accounts for MIDD and four SNPs previously reported to be associated with T2DM: A8296G, A12026G, T14577C, and T16189C (Kameoka et al. 1998; Tawata et al. 1998, 2000; Poulton et al. 2002b). Other than the A3243G SNP, we did not select SNPs associated with deafness. The A3243G SNP was found to be heteroplasmic in two FUSION families known to have sensorineural hearing loss and diabetes; no new families were identified. The SNPs at positions 8296 and 14577 were nonpolymorphic in our sample, and the variant at 12026 was extremely rare, present in only three cases and one control.

The SNP at position 16189 was previously reported associated with T2DM, lower ponderal index, and higher fasting insulin levels (Poulton et al. 1998, 2002b; Casteels et al. 1999). We did not observe significant association with T2DM (case frequency 0.246, control frequency $0.244 ; P=0.929)$. However among offspring,
${ }^{\mathrm{b}}$ Case frequencies based on 762 individuals for major haplogroups and 743 individuals for subgroups

${ }^{\mathrm{c}} \mathrm{Control}$ frequencies based on 402 individuals

$\mathrm{d}_{95 \%} \%$ Confidence interval

we observed evidence for association with quantitative traits in the same direction as previously observed (Casteels et al. 1999). Offspring with the $\mathrm{C}$ allele exhibited higher fasting serum insulin $(P$ value $=0.021)$, lower ponderal index $(P$ value $=0.043)$, and lower birthweight $(P$ value $=0.023)$ than those carrying the $\mathrm{T}$ allele $(\mathrm{Ta}-$ ble 3 ). Of these traits, only fasting insulin was measured in other groups; cases, spouse controls and elderly controls carrying the $\mathrm{C}$ allele also exhibited slightly higher fasting serum insulin levels compared to those carrying the $\mathrm{T}$ allele, but these increases were not significant ( $P$ values of $0.46,0.50$, and 0.96 , respectively).

Because SNP T16189C has been hypothesized to function by creating a homopolymeric cytosine (16184 93 polyC) tract, we genotyped known frequent SNPs that could disrupt the cytosine run, C16186T and C16192T (data not shown). 16186T was observed with $16189 \mathrm{C}$ in $27 \%$ of individuals assigned haplogroup $\mathrm{T}$. $16192 \mathrm{~T}$ was observed with $16189 \mathrm{C}$ in 83 and $2 \%$ of individuals assigned haplogroups U5b and U5a1, respectively, consistent with a previous report (Finnila et al. 2001), as well as two individuals assigned haplogroup $\mathrm{X}$. We repeated the test for association with quantitative traits in offspring comparing individuals with a likely homopolymeric cytosine run at 16184-93 to those where the run is disrupted by T at 16186,16189 or 16192. We still observed significant association with ponderal index and a trend toward significance with birthweight, but there is no longer an association with fasting insulin (Table 3). The homopolymeric run is not associated with T2DM status $(P=0.88)$.

We also used the FUSION sample to assess the evidence for maternal inheritance. Among FUSION 
Table 3 Phenotype trait associations $(P<0.05, N>10)$



$P$ values are adjusted for age, gender, and BMI, except weightrelated traits were not adjusted for BMI, and duration of diabetes and age at diabetes diagnosis were not adjusted for age. Means and standard deviations are from trait values prior to transformation

${ }^{a}$ Alternate calculations of significance: GEE $P=0.032$, mixed model with empirical variance estimator $P=0.033$

T2DM probands (average age of onset $51.0 \pm 8.3$ years old) with one affected parent, approximately 4.6-fold more recalled having a mother compared to a father affected or likely affected with T2DM (Table 4). Reported affection status of one or both of the probands' parents was missing with approximately equal frequency for mothers and fathers, and there was no significant difference between the reports of male versus female probands (not shown). However, among spouses unaffected with T2DM approximately 6.6-fold more recalled having a mother compared to a father affected or likely affected with T2DM (Table 4). These data suggest that a general recall bias may result in an overestimate of maternal transmission of diabetes to diabetic individuals.

To further examine this possibility we compared the proportion of affected offspring of male and female probands (Table 5). In this analysis parental diabetes is known from clinical examination and medical records, but the sample size is small because only 26 of the offspring had developed diabetes (average age of onset $36.0 \pm 5.2$ years old), 19 of which have a single affected parent. We found no difference in the proportion of affected offspring of female compared to male affected
${ }^{\mathrm{b}}$ Individuals assigned $\mathrm{C}$ at 16186,16189 , and 16192 compared to those with $\mathrm{T}$ at one or more positions. Individuals with missing 16189 genotypes were removed from analysis, as were individuals with C at 16189 but missing genotypes at 16186 or 16192

parents, 0.044 and 0.035 , respectively $(P=0.63)$. Although excess maternal inheritance would strengthen the hypothesis that mitochondrial variants affect susceptibility to T2DM, it is likely that mitochondrial variants have a small effect size, as has been observed for nuclearencoded variants (Florez et al. 2003), and thus one might not expect to detect a measurable difference in disease transmission.

\section{Discussion}

Recent technical advances have greatly improved the ability to test associations between mitochondrial variants and common disease. Improved sequencing technology has led to more sequenced mitochondrial genomes, which have revealed the evolutionary relatedness of detected variants more accurately. In addition, sequencing of many genomes has revealed recurrent SNPs that could affect haplogroup assignment if evaluated without reference to haplogenotype pattern. For example, G9055A, which tags subgroup $\mathrm{K}$, also is detected in some haplogroup $\mathrm{H}$ individuals; thus if we were assigning subgroup $\mathrm{K}$ based only on
Table 4 Inheritance of diabetes in the proband generation based on recalled parental affection status

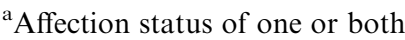
parents is unavailable

${ }^{\mathrm{b}}$ Calculated using individuals with exactly one affected parent

\begin{tabular}{|c|c|c|}
\hline T2DM affection status of parents & Number affected probands & Number unaffected spouses \\
\hline Affected mother, unaffected father & $337(42.4 \%)$ & $33(17.4 \%)$ \\
\hline Unaffected mother, affected father & $74(9.3 \%)$ & $5(2.6 \%)$ \\
\hline Unaffected mother, unaffected father & $254(32.0 \%)$ & $114(60.0 \%)$ \\
\hline Affected mother, affected father & $13(1.6 \%)$ & $3(1.6 \%)$ \\
\hline Missing parental affection status ${ }^{\mathrm{a}}$ & $117(14.7 \%)$ & $35(18.4 \%)$ \\
\hline Ratio of excess maternal inheritance ${ }^{b}$ & 4.6 & 6.6 \\
\hline
\end{tabular}


Table 5 Inheritance of diabetes in the offspring generation based on clinical diagnosis

\begin{tabular}{llll}
\hline $\begin{array}{l}\text { T2DM affection } \\
\text { status of parents }\end{array}$ & $\begin{array}{l}\text { Affected } \\
\text { offspring }\end{array}$ & $\begin{array}{l}\text { Unaffected } \\
\text { offspring }\end{array}$ & $\begin{array}{l}\text { Percent offspring } \\
\text { affected }\end{array}$ \\
\hline $\begin{array}{l}\text { Affected mother, unaffected father } \\
\text { Unaffected mother, affected father }\end{array}$ & 7 & 151 & $4.4 \%$ \\
\hline
\end{tabular}

the 9055 genotype, we could incorrectly assign $\mathrm{K}$ to a subset of haplogroup $\mathrm{H}$.

Our genotype data for 32 mitochondrial SNPs on 1,164 individuals provide additional information to resolve SNP origins. The genotype data suggest the relative order in which two pairs of SNPs tagging the same haplogroup arose. Within haplogroup V, three samples exhibit C15904T but not G4580A, suggesting that C15904T arose before G4580A. Within haplogroup W, 11 samples exhibit G8994A but not C7864T, suggesting that G8994A arose before C7864T. Some genotype data revealed new instances of recurrent variation, including that G9055A appears in haplogroup $\mathrm{H}$ in seven samples with T7028C and that A14793G appears in haplogroup V in five samples with G4580A and C15904T. Previously unobserved haplogenotype patterns are denoted in Table 1.

To determine whether common maternal lineages predispose to T2DM, we tested eight major haplogroups and 13 subgroups for association with T2DM in 762 cases and 402 controls. To our knowledge, this is the largest published sample used to test for association between mitochondrial variants and T2DM. No significant association with major haplogroups was found in previous smaller studies, which had more limited power to detect such effects (Thomas et al. 1996; Sherratt et al. 1999). In our sample, the maternal lineage showing the most significant excess in cases compared to controls was haplogroup $\mathrm{J}(\mathrm{OR}=1.69, P=0.056)$, a result that became slightly more significant after excluding 74 cases with paternal inheritance of diabetes $(\mathrm{OR}=1.77$, $P=0.045)$. Although a Bonferroni correction for multiple tests is too conservative because the haplogroups are not independent, this level of significance is still probably consistent with that expected by chance given the 21 tests. Haplogroup $\mathbf{J}$ contains a series of mutations that could lead to partial uncoupling of ATP generation from heat production (Wallace et al. 1999), and it has been shown to be associated with other disorders in individuals of European ancestry, including decreased risk of Parkinson's disease (van der Walt et al. 2003) and increased penetrance of Leber's hereditary optic neuropathy (Wallace et al. 1999). Other haplogroups slightly more frequent in cases than controls include $\mathrm{K}$ and the subgroup of $\mathrm{H} 1$ harboring the A8271T variant.

Among the intermediate phenotypes studied, we observed several that were associated with a particular haplogroup (Table 3), although the number of tests significant with $P$ values below 0.05 is actually less than that expected by chance. While this low proportion of significant results may indicate that none of the associations are true positives, one or more of these haplogroups may influence a diabetes-related trait with a small effect.
For a complex disease such as T2DM, many variants with modest effect may influence susceptibility, although observing small effects requires very large sample sizes.

Consistent with previous studies (Poulton et al. 1998, 2002a; Casteels et al. 1999), we observed support for a role of T16189C in susceptibility to T2DM-related traits. In offspring, we initially confirmed the association of T16189C with higher fasting insulin and reduced ponderal index (Table 3), as had been reported, and also observed association with reduced birthweight, a trait likely correlated with ponderal index. We failed to confirm the role of the T16189C variant in susceptibility to diabetes status, as had been observed in one study (Poulton et al. 2002b) but not in another (Gill-Randall et al. 2001). The T16189C variant is located in a cytosine run within the noncoding D-loop region of mitochondrial DNA, close to sequences that are conserved across multiple species that may be the origin of bidirectional replication initiation and that may be involved in regulation of replication and transcription (Sbisa et al. 1997; Yasukawa et al. 2005). The $\mathrm{C}$ allele likely causes the variability in length of this cytosine tract (Poulton et al. 1998), which may ultimately affect mitochondrial function during fetal pancreatic development, influencing adult insulin levels. After excluding individuals with genotypes that would disrupt the 16184-93 polyC tract at positions 16186 or 16192 , we still observed support for the role of $\mathrm{T} 16189 \mathrm{C}$ in ponderal index and birthweight. As observed previously (Richards et al. 1998), the T16189C variant in the hypervariable D-loop region was found in individuals with many different haplogroups, suggesting that it has arisen multiple times on different haplogroup backgrounds (data not shown).

Given the low frequency of many haplogroups and subgroups tested, even our sample of 762 cases and 402 controls had limited power to detect susceptibility variants. The power to detect true susceptibility alleles of small effect would be modest, especially for the many relatively rare haplogroups. For example, the most common haplogroup observed $(\mathrm{H}$, allele frequency 0.485 ) has $50 \%$ power to detect an allele with OR of 1.27 , while the least common subgroup (U8, allele frequency 0.010 ) has $50 \%$ power to detect an OR of 2.80 . The large number of association tests increases the chance that false positive results would obscure a true susceptibility effect. Thus, these results should be interpreted with caution until replicated in additional studies. The power for association with some quantitative traits is also limited because not all traits were examined in all individuals. For example, the FSIGT trait of insulin sensitivity was measured in only 380 unaffected offspring and 144 unaffected spouses. 
We did not find convincing evidence of excess maternal transmission of diabetes to the probands when we took into account the excess maternal versus paternal diabetes reported by their unaffected spouses. Both probands and their unaffected spouses reported at least a fourfold higher prevalence of diabetes in mothers than in fathers. This recall bias is consistent with most of the previous studies (Alcolado et al. 2002). We also found no difference in the proportion of affected offspring between male and female probands for whom diabetes status is known from clinical examination and medical records. We had good $(96 \%)$ power to detect even a twofold difference between maternal and paternal transmission to the offspring, and we failed to find an effect even approaching that magnitude.

While none of the haplogroups tested show a strong effect on diabetes susceptibility, future genetic analyses of T2DM susceptibility may be able to build on this analysis. Larger sample sizes are necessary to confirm or refute the potential role of the susceptibility variants described here. Future studies could evaluate the impact of mitochondrial variants on diabetic complications, which may be affected by mitochondrial overproduction of superoxide (Brownlee 2001; Evans et al. 2003). In addition, mitochondrial variants on a particular haplogroup may increase the penetrance of nuclear-encoded mutations, so haplogroup assignment could be used to assess gene-gene interactions that contribute to T2DM and related traits.

Acknowledgments The FUSION study was funded by intramural funds from the NHGRI project OH95-C-N030, and by National Institutes of Health grants DK62370 and HG00376 to M.B. J.T. has been partially supported by the Academy of Finland (38387, 46558). R.N.B. was supported by NIH grants DK27619 and DK29867. R.M.W. is supported by the American Diabetes Association. K.L.M. is the recipient of a Burroughs Wellcome Career Award in the Biomedical Sciences. We thank Joanna Poulton for helpful comments.

\section{References}

Alcolado JC, Laji K, Gill-Randall R (2002) Maternal transmission of diabetes. Diabet Med 19:89-98

Andrews RM, Kubacka I, Chinnery PF, Lightowlers RN, Turnbull DM, Howell N (1999) Reanalysis and revision of the Cambridge reference sequence for human mitochondrial DNA. Nat Genet 23:147

Antonetti DA, Reynet C, Kahn CR (1995) Increased expression of mitochondrial-encoded genes in skeletal muscle of humans with diabetes mellitus. J Clin Invest 95:1383-1388

Barrett TG (2001) Mitochondrial diabetes, DIDMOAD and other inherited diabetes syndromes. Best Pract Res Clin Endocrinol Metab 15:325-343

Brown MD, Starikovskaya E, Derbeneva O, Hosseini S, Allen JC, Mikhailovskaya IE, Sukernik RI, Wallace DC (2002) The role of mtDNA background in disease expression: a new primary LHON mutation associated with Western Eurasian haplogroup. J Hum Genet 110:130-138

Brownlee M (2001) Biochemistry and molecular cell biology of diabetic complications. Nature 414:813-820

Casteels K, Ong K, Phillips D, Bendall H, Pembrey M (1999) Mitochondrial 16189 variant, thinness at birth, and type-2 diabetes. ALSPAC study team. Avon longitudinal study of pregnancy and childhood. Lancet 353:1499-1500

Evans JL, Goldfine ID, Maddux BA, Grodsky GM (2003) Are oxidative stress-activated signaling pathways mediators of insulin resistance and beta-cell dysfunction? Diabetes 52:1-8

Finnila S, Lehtonen MS, Majamaa K (2001) Phylogenetic network for European mtDNA. Am J Hum Genet 68:1475-1484

Florez JC, Hirschhorn J, Altshuler D (2003) The inherited basis of diabetes mellitus: implications for the genetic analysis of complex traits. Annu Rev Genomics Hum Genet 4:257-291

Ghosh S, Watanabe RM, Valle TT, Hauser ER, Magnuson VL, Langefeld CD, Ally DS, Mohlke KL, Silander K, Kohtamaki K, Chines P, Balow Jr J, Birznieks G, Chang J, Eldridge W, Erdos MR, Karanjawala ZE, Knapp JI, Kudelko K, Martin C, Morales-Mena A, Musick A, Musick T, Pfahl C, Porter R, Rayman JB, Rha D, Segal L, Shapiro S, Sharaf R, Shurtleff B, So A, Tannenbaum J, Te C, Tovar J, Unni A, Welch C, Whiten R, Witt A, Blaschak-Harvan J, Douglas JA, Duren WL, Epstein MP, Fingerlin TE, Kaleta HS, Lange EM, Li C, McEachin RC, Stringham HM, Trager E, White PP, Eriksson J, Toivanen L, Vidgren G, Nylund SJ, Tuomilehto-Wolf E, Ross EH, Demirchyan E, Hagopian WA, Buchanan TA, Tuomilehto J, Bergman RN, Collins FS, Boehnke M (2000) The FinlandUnited States investigation of non-insulin-dependent diabetes mellitus genetics (FUSION) study. I. An autosomal genome scan for genes that predispose to type 2 diabetes. Am J Hum Genet 67:1174-1185

Gill-Randall R, Sherratt EJ, Thomas AW, Gagg JW, Lee A, Alcolado JC (2001) Analysis of a polycytosine tract and heteroplasmic length variation in the mitochondrial DNA D-loop of patients with diabetes, MELAS syndrome and race-matched controls. Diabet Med 18:413-416

Herrnstadt C, Elson JL, Fahy E, Preston G, Turnbull DM, Anderson C, Ghosh SS, Olefsky JM, Beal MF, Davis RE, Howell N (2002) Reduced-median-network analysis of complete mitochondrial DNA coding-region sequences for the major African, Asian, and European haplogroups. Am J Hum Genet 70:1152-1171

Kameoka K, Isotani H, Tanaka K, Azukari K, Fujimura Y, Shiota Y, Sasaki E, Majima M, Furukawa K, Haginomori S, Kitaoka H, Ohsawa N (1998) Novel mitochondrial DNA mutation in tRNA(Lys) (8296A-> G) associated with diabetes. Biochem Biophys Res Commun 245:523-527

Kaprio J, Tuomilehto J, Koskenvuo M, Romanov K, Reunanen A, Eriksson J, Stengard J, Kesaniemi YA (1992) Concordance for type 1 (insulin-dependent) and type 2 (non-insulin-dependent) diabetes mellitus in a population-based cohort of twins in Finland. Diabetologia 35:1060-1067

Kelley DE, He J, Menshikova EV, Ritov VB (2002) Dysfunction of mitochondria in human skeletal muscle in type 2 diabetes. Diabetes 51:2944-2950

King H, Aubert RE, Herman WH (1998) Global burden of diabetes, 1995-2025: prevalence, numerical estimates, and projections. Diabet Care 21:1414-1431

Littell RC, Milliken GA, Stroup WW, Wolfinger RD (1996) SAS system for mixed models. SAS Institute, Cary

Maca-Meyer N, Gonzalez AM, Larruga JM, Flores C, Cabrera VM (2001) Major genomic mitochondrial lineages delineate early human expansions. BMC Genet 2:13

Macaulay V, Richards M, Hickey E, Vega E, Cruciani F, Guida V, Scozzari R, Bonne-Tamir B, Sykes B, Torroni A (1999) The emerging tree of West Eurasian mtDNAs: a synthesis of controlregion sequences and RFLPs. Am J Hum Genet 64:232-249

Maechler P, Wollheim CB (2001) Mitochondrial function in normal and diabetic beta-cells. Nature 414:807-812

Marchington DR, Poulton J, Sellar A, Holt IJ (1996) Do sequence variants in the major non-coding region of the mitochondrial genome influence mitochondrial mutations associated with disease? Hum Mol Genet 5:473-479

McCarthy MI (2004) Progress in defining the molecular basis of type 2 diabetes mellitus through susceptibility-gene identification. Hum Mol Genet 13:R33-R41 
Mohlke KL, Erdos MR, Scott LJ, Fingerlin TE, Jackson AU, Silander K, Hollstein P, Boehnke M, Collins FS (2002) Highthroughput screening for evidence of association by using mass spectrometry genotyping on DNA pools. Proc Natl Acad Sci USA 99:16928-16933

Mokdad AH, Ford ES, Bowman BA, Dietz WH, Vinicor F, Bales VS, Marks JS (2003) Prevalence of obesity, diabetes, and obesity-related health risk factors, 2001. JAMA 289:76-79

Mootha VK, Lindgren CM, Eriksson KF, Subramanian A, Sihag S, Lehar J, Puigserver P, Carlsson E, Ridderstrale M, Laurila E, Houstis N, Daly MJ, Patterson N, Mesirov JP, Golub TR, Tamayo P, Spiegelman B, Lander ES, Hirschhorn JN, Altshuler D, Groop LC (2003) PGC-1alpha-responsive genes involved in oxidative phosphorylation are coordinately downregulated in human diabetes. Nat Genet 34:267-273

Newman B, Selby JV, King MC, Slemenda C, Fabsitz R, Friedman GD (1987) Concordance for type 2 (non-insulindependent) diabetes mellitus in male twins. Diabetologia 30:763-768

van den Ouweland JM, Lemkes HH, Ruitenbeek W, Sandkuijl LA, de Vijlder MF, Struyvenberg PA, van de Kamp JJ, Maassen JA (1992) Mutation in mitochondrial tRNA(Leu)(UUR) gene in a large pedigree with maternally transmitted type II diabetes mellitus and deafness. Nat Genet 1:368-371

Petersen KF, Dufour S, Befroy D, Garcia R, Shulman GI (2004) Impaired mitochondrial activity in the insulin-resistant offspring of patients with type 2 diabetes. N Engl J Med 350:664-671

Pettitt DJ, Aleck KA, Baird HR, Carraher MJ, Bennett PH, Knowler WC (1988) Congenital susceptibility to NIDDM. Role of intrauterine environment. Diabetes 37:622-628

Poulton J, Das S (2004) Correction: no evidence of an association between the T16189C mtDNA variant and late onset dementia. J Med Genet 41:957

Poulton J, Brown MS, Cooper A, Marchington DR, Phillips DI (1998) A common mitochondrial DNA variant is associated with insulin resistance in adult life. Diabetologia 41:54-58

Poulton J, Bednarz AL, Scott-Brown M, Thompson C, Macaulay VA, Simmons D (2002a) The presence of a common mitochondrial DNA variant is associated with fasting insulin levels in Europeans in Auckland. Diabet Med 19:969-971

Poulton J, Luan J, Macaulay V, Hennings S, Mitchell J, Wareham NJ (2002b) Type 2 diabetes is associated with a common mitochondrial variant: evidence from a population-based casecontrol study. Hum Mol Genet 11:1581-1583

Reardon W, Ross RJ, Sweeney MG, Luxon LM, Pembrey ME, Harding AE, Trembath RC (1992) Diabetes mellitus associated with a pathogenic point mutation in mitochondrial DNA. Lancet 340:1376-1379

Rich SS (1990) Mapping genes in diabetes. Genetic epidemiological perspective. Diabetes 39:1315-1319

Richards M, Corte-Real H, Forster P, Macaulay V, WilkinsonHerbots H, Demaine A, Papiha S, Hedges R, Bandelt HJ, Sykes B (1996) Paleolithic and neolithic lineages in the European mitochondrial gene pool. Am J Hum Genet 59:185-203

Richards MB, Macaulay VA, Bandelt HJ, Sykes BC (1998) Phylogeography of mitochondrial DNA in western Europe. Ann Hum Genet 62 (Pt 3):241-260

Sbisa E, Tanzariello F, Reyes A, Pesole G, Saccone C (1997) Mammalian mitochondrial D-loop region structural analysis: identification of new conserved sequences and their functional and evolutionary implications. Gene 205:125-140

Sherratt EJ, Thomas AW, Gagg JW, Majid A, Alcolado JC (1999) Mitochondrial DNA variations in patients with Type 2 (noninsulin dependent) diabetes mellitus and a Welsh control population. Hum Mutat 13:412-413

Silander K, Scott LJ, Valle TT, Mohlke KL, Stringham HM, Wiles KR, Duren WL, Doheny KF, Pugh EW, Chines P, Narisu N, White PP, Fingerlin TE, Jackson AU, Li C, Ghosh S, Magnuson VL, Colby K, Erdos MR, Hill JE, Hollstein P, Humphreys KM, Kasad RA, Lambert J, Lazaridis KN, Lin G, Morales-Mena A, Patzkowski K, Pfahl C, Porter R, Rha D,
Segal L, Suh YD, Tovar J, Unni A, Welch C, Douglas JA, Epstein MP, Hauser ER, Hagopian W, Buchanan TA, Watanabe RM, Bergman RN, Tuomilehto J, Collins FS, Boehnke M (2004) A large set of Finnish affected sibling pair families with type 2 diabetes suggests susceptibility loci on chromosomes 6, 11, and 14. Diabetes 53:821-829

Silva JP, Kohler M, Graff C, Oldfors A, Magnuson MA, Berggren PO, Larsson NG (2000) Impaired insulin secretion and beta-cell loss in tissue-specific knockout mice with mitochondrial diabetes. Nat Genet 26:336-340

Silverman BL, Rizzo T, Green OC, Cho NH, Winter RJ, Ogata ES, Richards GE, Metzger BE (1991) Long-term prospective evaluation of offspring of diabetic mothers. Diabetes 40:121-125

Simoneau JA, Kelley DE (1997) Altered glycolytic and oxidative capacities of skeletal muscle contribute to insulin resistance in NIDDM. J Appl Physiol 83:166-171

Suzuki Y, Iizuka T, Kobayashi T, Nishikawa T, Atsumi Y, Kadowaki T, Oka Y, Kadowaki H, Taniyama M, Hosokawa K, Asahina T, Matsuoka K (1997) Diabetes mellitus associated with the 3243 mitochondrial tRNA(Leu)(UUR) mutation: insulin secretion and sensitivity. Metabolism 46:1019-1023

Tawata M, Ohtaka M, Iwase E, Ikegishi Y, Aida K, Onaya T (1998) New mitochondrial DNA homoplasmic mutations associated with Japanese patients with type 2 diabetes. Diabetes 47:276-277

Tawata M, Hayashi JI, Isobe K, Ohkubo E, Ohtaka M, Chen J, Aida K, Onaya T (2000) A new mitochondrial DNA mutation at $14577 \mathrm{~T} / \mathrm{C}$ is probably a major pathogenic mutation for maternally inherited type 2 diabetes. Diabetes 49:1269-1272

Thomas AW, Edwards A, Sherratt EJ, Majid A, Gagg J, Alcolado JC (1996) Molecular scanning of candidate mitochondrial tRNA genes in type 2 (non-insulin dependent) diabetes mellitus. J Med Genet 33:253-256

Torroni A, Huoponen K, Francalacci P, Petrozzi M, Morelli L, Scozzari R, Obinu D, Savontaus ML, Wallace DC (1996) Classification of European mtDNAs from an analysis of three European populations. Genetics 144:1835-1850

Torroni A, Petrozzi M, D'Urbano L, Sellitto D, Zeviani M, Carrara F, Carducci C, Leuzzi V, Carelli V, Barboni P, De Negri A, Scozzari R (1997) Haplotype and phylogenetic analyses suggest that one European-specific mtDNA background plays a role in the expression of Leber hereditary optic neuropathy by increasing the penetrance of the primary mutations 11778 and 14484. Am J Hum Genet 60:1107-1121

Tuomilehto J, Korhonen HJ, Kartovaara L, Salomaa V, Stengard JH, Pitkanen M, Aro A, Javela K, Uusitupa M, Pitkaniemi J (1991) Prevalence of diabetes mellitus and impaired glucose tolerance in the middle-aged population of three areas in Finland. Int J Epidemiol 20:1010-1017

Valle T, Tuomilehto J, Bergman RN, Ghosh S, Hauser ER, Eriksson J, Nylund SJ, Kohtamaki K, Toivanen L, Vidgren G, Tuomilehto-Wolf E, Ehnholm C, Blaschak J, Langefeld CD, Watanabe RM, Magnuson V, Ally DS, Hagopian WA, Ross E, Buchanan TA, Collins F, Boehnke M (1998) Mapping genes for NIDDM. Design of the Finland-United States Investigation of NIDDM Genetics (FUSION) Study. Diabet Care 21:949-958 Wallace DC, Brown MD, Lott MT (1999) Mitochondrial DNA variation in human evolution and disease. Gene 238:211-230

van der Walt JM, Nicodemus KK, Martin ER, Scott WK, Nance MA, Watts RL, Hubble JP, Haines JL, Koller WC, Lyons K, Pahwa R, Stern MB, Colcher A, Hiner BC, Jankovic J, Ondo WG, Allen FH, Jr, Goetz CG, Small GW, Mastaglia F, Stajich JM, McLaurin AC, Middleton LT, Scott BL, Schmechel DE, Pericak-Vance MA, Vance JM (2003) Mitochondrial polymorphisms significantly reduce the risk of Parkinson disease. Am J Hum Genet 72:804-811

Yasukawa T, Yang MY, Jacobs HT, Holt IJ (2005) A bidirectional origin of replication maps to the major noncoding region of human mitochondrial DNA. Mol Cell 18:651-662

Zeger SL, Liang KY (1986) Longitudinal data analysis for discrete and continuous outcomes. Biometrics 42:121-130 